\title{
EL INVENTOR DE LA CUADRIGA
}

\author{
Rafael Rodríguez Díaz
}

uriga quiere decir: "el que tiene las riendas". Con este
nombre nos referimos a la constelación que ha sido llama-
da también el Cochero o el Conductor. (Ruiz de Elvira: 476).

El Auriga consta básicamente de una especie de pentágono, y la nomenclatura de sus principales estrellas es la siguiente: Capella $(\alpha)^{*}$, Menkalinan $(ß)^{* *}$, Almaaz $(\varepsilon)$, Sadatoni $(\zeta)$ y Attawabi $(\tau)$. La figura básica del Auriga es esta:

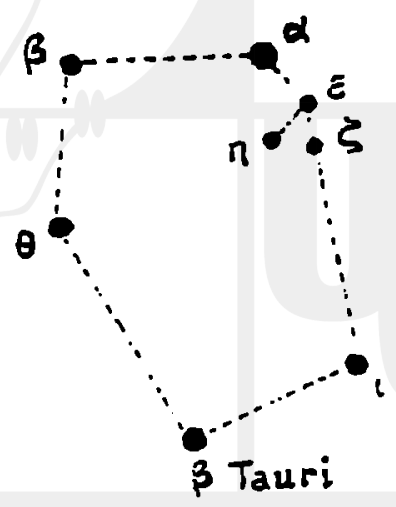

- Capella es la alfa Aurigae; significa: "la Cabra". (Paronelli y Meliá: 40).

* Menkalinan es la beta Aurigae; significa: "el hombro del que sostiene las riendas". (De Gortari: 100). 
Sin embargo, debemos hacer algunas "observaciones"; primera, una de las estrellas del pentágono es compartida con otra constelación; se trata de la beta del Toro. De hecho, el nombre de esa estrella es $E l$ Nath, "la corneadora" y representa uno de los cuernos del Toro. Sobre la punta del cuerno, pues, va a estar apoyado el pie izquierdo del Auriga, según veremos en el dibujo de la constelación.

No se trata, entonces, de que el Auriga y el Toro compartan su estrella beta, tal como lo sugiere equivocadamente un autor. (Chartrand: 118). Cada una de esas constelaciones tiene su beta correspondiente. La beta del Toro sólo sirve de "apoyo" al Auriga y no se le da una nomenclatura especial dentro de esta constelación. (Paluzie Borrell: 392; Chartrand: Ibid.).

La segunda "observación" tiene que ver con la Capella, la alfa Aurigae. Estamos ante una estrella de primera magnitud, con propiedades físicas semejantes a las de nuestro sol, aunque es mucho más grande que él. La luminosidad de Capella es 150 veces mayor que la del sol y su diámetro es 14 veces más grande. A la distancia que está Capella, nuestro sol no sería visible a simple vista va que su magnitud sería de 6.5. (Enciclopedia Universal Ilustrada: XIII, 1191; Paluzie Borrel: 392).

Otra característica importante de Capella es que se trata de una estrella doble, y sus componentes describen una órbita completa en menos de cuatro meses, tiempo muy corto si se compara con otros sistemas binarios de estrellas que tardan millones de años en completar sus órbitas. (Comellas: 41).

El par de la Capella hace la sexta estrella más brillante del cielo (Chartrand: Ibid) y una de las tres estrellas más hermosas del cielo boreal; las otras son: Vega, de color blanco, y Arturo, de color amarillo. Capella tiene un color comprendido entre ambas: es de un color amarillo dorado. (Paronelli y Meliá: 40-41; Historia Universal Ilustrada: Enciclopedia: Ibid).

Capella, la Cabra, está acompañada de dos Cabritillos. Estos, están representados en las estrellas épsilon $(\varepsilon)$, zeta $(\zeta)$ y eta $(\eta)$ de la constelación del Auriga. (Chartrand: Ibid.).

Pasemos a conocer ahora los relatos mitológicos que les dan 
vida a los personajes representados en nuestra constelación. El primer personaje es, precisamente, la Cabra; la cual está personificada - tal como ya explicamos- en la estrella alfa Aurigae.

En la figura de la constelación, la Cabra aparece en el hombro del Auriga junto con dos Cabritillos. El relato mitológico no dice nada acerca de la identidad de los dos Cabritillos, pero sí de la Cabra. Como esta está apoyada en el codo del Auriga, se le llama también "olenia" ("del codo"). (Ruiz de Elvira: 53; 476).

Varias fueron las nodrizas que alimentaron a Zeus mientras permaneció escondido en un monte de Creta. Ya conocimos la identidad de algunas de ellas - Calisto y Cinosura- convertidas por Zeus en las Osas Mayor y Menor. Existen otros nombres para esas nodrizas; por ejemplo: Adrastea, Ida y Amaltea, hijas del rey Meliso. Sobre Amaltea, algunas versiones la hacen ninfa y otras dicen que se trataba de una cabra con cuya leche alimentaron las otras dos nodrizas al dios infante. También lo alimentaron con miel, sugerido esto último por el nombre del rey Meliseo. (Ruiz de Elvira: 52). La leche alimenticia de la Cabra Amaltea puede ser símbolo de la humedad fecundante esparcida por las tempestades en la cima de las montañas del Ida, sostiene un autor. (Steuding: 30).

De la Cabra Amaltea se dice, además, que era hija del Sol y de aspecto pavoroso. (Ruiz de Elvira: 53). Uno de los cuernos de la Cabra era anómalo, como de vaca. Un día, la Cabra rompió el cuerno contra un árbol. Entonces, Zeus lo tomó y lo convirtió en la Cornucopia o Cuerno de la abundancia; llamado así porque siempre estaba lleno de todos los frutos, flores, alimentos y bebidas que su poseedor podía desear. (Graves: I, 45; Gebhardt: I, 15).

Zeus utilizó la piel de la Cabra Amaltea para hacerse un escudo llamado égida que le sirvió de protección durante la Titanomaquia o lucha contra los Titanes. (Ruiz de Elvira: 476). La égida hacia invencible a quien la portara. Por otra parte, la égida o malla protectora que llevaba Atenea sobre el pecho o sobre un brazo, pudo haber sido hecha también de la piel de la Cabra Amaltea. (Gebhardt: I, 15, 59).

El relato mitológíco dice que Zeus revistió de una nueva piel a la Cabra Amaltea, la resucitó y, por último, la catasterizó. (Ruiz de Elvira: Ibid.). Aunque una versión añade que la imagen de Amaltea 
fue puesta entre las estrellas como la constelación de Capricornio. (Graves: Ibid.).

En cuanto a la identidad del Cochero o Auriga existen múltiples versiones. Una dice que se trata de Erictonio, el rey de Atenas inventor de la cuadriga. (Ruiz de Elvira: 476).

Esta versión está enmarcada dentro de una amplia historia que comienza desde los variados orígenes de los seres humanos. Porque según la mitologia griega los humanos podían tener diversos orígenes; por ejemplo, podían proceder, por metamorfosis, de las hormigas. Es el caso de los mirmidones, grupo que aparece en la Ilíada formando parte de los ejércitos de Aquiles.

También podían derivar los humanos de árboles, de rocas o piedras, como los arcadios, "nacidos de rocas y de roble". Esto último tiene que ver con algunos descendientes de Deucalión y Pirra. El episodio de esta pareja que sobrevivió al diluvio universal, ya lo conocemos en parte. Nos falta agregar que, ya asentados en tierra seca, Deucalión y Pirra fueron exigidos por Zeus a procrear una nueva raza humana. Para eso, debieron arrojar piedras hacia atrás, por encima de sus cabezas. De las piedras que lanzó Deucalión nacieron hombres y de las que lanzó Pirra brotaron mujeres. (Ruiz de Elvira: 108-109).

Erictonio pertenece a un grupo o tipo humano llamado de los autóctonos porque se dice que brotaron directamente de la tierra, con o sin intervención de un dios como padre.

Pues bien, el origen de Erictonio fue el siguiente: Atenea llegó a la fragua de Hefesto porque este estaba haciendo unas armas para ella. En un momento dado, Hefesto quiso violar a Atenea, pero la diosa se defendió denodadamente. Sin embargo, Hefesto eyaculó encima del muslo de Atenea; ella se limpió el semen con un puñado de lana y luego lo arrojó con asco sobre la diosa Tierra, la cual quedó fertilizada accidentalmente. (Ruiz de Elvira: 109-110; Graves: I, 116-117).

La Tierra se negó a reconocer a Erictonio como su hijo. A pesar de eso, el nombre del niño hace referencia a su origen terráqueo ya que sus componentes son: erión = lana o eris = lucha (por la lana con que se limpió Atenea o por la lucha que libró contra 
Hefesto) y chthonos = tierra. (Graves: I, $116-117 ; 119$ ).

Atenea acogió al niño como si fuera hijo suyo, pero lo ocultó en un cesto para evitar las burlas de Hefesto. El cesto fue entregado a tres muchachas - Aglauro, Herse y Pándroso-, hijas del rey ateniense Cécrope, de quien se dice que era en parte hombre y en parte, serpiente. Atenea les había dado el encargo a las jóvenes de que por nada del mundo vieran lo que había en el cesto. No hicieron caso y atisbaron debajo de la tapa de la cesta. Al ver ahí a un niño con cola de serpiente en vez de piernas, las tres se volvieron locas y se suicidaron arrojándose desde lo alto de la Acrópolis.

Una corneja o un cuervo le llevó la noticia a Atenea; entonces la diosa dejó caer una enorme roca que transportaba para fortificar la ciudad, convirtiéndose la roca en un monte: el Licabeto. Al cuervo que le había llevado la noticia, la diosa le cambió el color de blanco a negro y prohibió a perpetuidad a todos los cuervos o cornejas que volvieran a habitar en la Acrópolis. (Ruiz de Elvira: 353354; Graves: I: 117-118).

Erictonio se refugió en la égida de Atenea y la diosa lo crió luego tan tiernamente que para muchos Erictonio debía ser considerado verdadero hijo de la diosa. De hecho, cuando Erictonio llegó a ser rey de Atenas, en sustitución de Anfictión, instituyó el culto de Atenea y enseñó a sus conciudadanos el uso de la plata. (Ruiz de Elvira: 354; Graves: I, 118).

Ahora bien, surge la pregunta; ¿y por qué está relacionado Erictonio con la cuadriga o carro tirado por cuatro caballos? De entrada, hay un autor que dice: "el impedimento de Erictonio lo llevó a inventar el carro de ruedas (cuadriga)". (Chartrand: 118).

Pero, seguimos intrigados: ¿cuál impedimento? Para comenzar, recordemos que Erictonio está asociado a un ser híbrido mitad humano y mitad serpiente. Indaguemos más sobre este punto $\mathrm{v}$ tal vez descubramos la conexión de Erictonio con el carro tirado por cuatro caballos o cuadriga.

De entrada, nos llama la atención la identificación de Erictonio con Erecteo, el cual fue también rey de Atenas. Se atribuyen, sin más, las características del primero al segundo: su nacimiento a partir de la fecundación de la tierra por parte de Hefesto; la pro- 
tección que le dio Atenea al ocultarlo en un cesto; cómo al destapar el cesto las nodrizas encontraron un niño con una serpiente enroscada en sus pies (variante del niño con cola de serpiente).

Se añaden algunos datos más: al ceñir Erecteo (Erictonio) la corona de Atenas, elevó un templo dividido en dos: una parte dedicada a Atenea y la otra a Pandrosa (Pándroso), en gratitud a esa hija de Cecrops (Cécrope) que lo amparó en su abandono. (Gebhardt: $I, 62)$.

Las asimiiaciones continúan: la antigua familia real de Atenas pretendia descender de Erictonio y Erecteo, y sus miembros se llamaban a sí mismos erectidas; solían llevar serpientes doradas como amuletos y guardaban una serpiente sagrada en el Erecteón (o templo dedicado a Erictonio-Erecteo). Erictonio era también un viento procreador proveniente de las montañas cubiertas de brezos, y a él se consagraban las parejas de recién casados de Atenas para asegurar su fertilidad. (Graves: I, 120).

Sin embargo, es posible diferenciar a los dos personajes: Erecteo y Erictonio. El primero es considerado sucesor del rey ateniense Pandión y hermano gemelo de Butes, quien formó parte de los Argonautas y llegó a ser sacerdote de Atenea y Posidón. El segundo, Erictonio,es uno de los fundadores de la ciudad de Troya. (Graves: I, 207; II, 326-330).

Y aquí vienen las desaveniencias entre la identidad de los dos personajes: Erecteo fue padre de Cécrope, Procris (esposa de Céfalo),Oritía y otras cinco hijas más. Si Erecteo fue padre de Cécrope, su sucesor en el reino de Atenas, no puede ser al mismo tiempo Erictonio, quien de niño fue encargado en el cesto a las tres hijas de Cécrope: Aglauro, Herse y Pándroso, tal como vimos antes.

En cuanto hermano gemelo de Butes, Erecteo está asociado a un héroe oracular con cola de serpiente, mientras que de su hermano Butes se dice que consulta a un oráculo abeja. Los dos son hijos de Zeuxipe, "la que unce caballos", es decir, de la diosa Démeter con cabeza de yegua. (Graves: I, 206).

El Erictonio de estirpe troyana tiene la siguiente parentela: Dárdano (de donde viene el Estrecho de los Dardanelos, a cuya 
entrada fue levantada la ciudad de Troya) tuvo tres hijos: Do (de donde proviene uno de los nombres de Troya: Ilión), Ideo y Erictonio. De este nació Troz (de cuyo nombre se originó el de Troya). (Graves: $\Pi$, 327-330).

Ahora bien, los dos personajes, Erecteo y Erictonio -el ateniense y el troyano- van a ser asociados de nuevo por obra y gracia de un tercer personaje: Bóreas, quien, además nos va a dar la clave de la vinculación de Erictonic con la cuadriga.

Bóreas o Viento del Norte estaba enamorado de Oritía, hija del rey ateniense Erecteo. Como este se negara a concederle la mano de su hija, Bóreas tomó a Oritía con sus alas y, envuelto en un manto de nubes negras, la violó. De Bóreas se dice que tenía en vez de pies colas de serpiente. (Gravez: I, 210).

Erictonio era un rey cretense o troyano, propietario de tres mil yeguas. Bóreas se enamoró de ellas y, disfrazado de semental, cubrió a doce de ellas. De esa unión nacieron doce potrancas que podían correr sobre espigas de trigo sin doblarlas y sobre las crestas de las olas. También se dice que las doce potrancas servirían para tirar de tres carros de cuatro caballos, simbolizando cada uno de estos carros las estaciones de Primavera, Verano y Otoño. (Graves: I, 211-212; 1I, 329).

Con todos estos elementos tenemos ya resuelto el enigma de la asociación de Erictonio y la cuadriga. Como Erecteo o Erictonio, el personaje está conectado con las serpientes y el viento. En cuanto tal, necesita "montarse" en carros de cuatro caballos o yeguas, para presentarse como símbolo de fecundidad.

Erictonio-Erecteo, más que un rey (ateniense o troyano) de carne y hueso, fue un personaje mítico, encarnación de un poderío que comenzó siendo debilidad. Como Zeus, Erictonio necesitó ser protegido y criado por nodrizas; después llegaría a ser un personaje poderoso .

Por eso, en la figura de la constelación aparece cargando en su espalda a la Cabra Amaltea: en recuerdo, quizás, de la necesidad de cuido que Erictonio tuvo cuando niño.

Señalemos algunas curiosidades más: al Auriga o Cochero de hecho debería llamársele cuadrigario porque así se le conocía al 
auriga que guiaba carros de cuatro caballos. (Enciclopedia Universal Ilustrada: XVI, 791). Como signo de su oficio, el Cochero ostenta únicamente la fusta. (Paronelli y Meliá: 40-41).

Para finalizar, digamos que en la constelación del Cochero algunos han querido ver a Posidón surgiendo en su carro desde el mar (Chartrand: 118); otros, a Belerofontes o a Hipólito, víctima este último de un accidente en su cuadriga, luego de su trágico amor con su madrastra Fedra. (Ruiz de Elvira: 380-381; 476).

25 de abril de 1994.

\section{Bibliografía}

1 Mark R. Chartrand III. Skyguide. a fiel guide to the heavens. Golden Press. New York. Westem Publishing company. Inc. Racines. Wiscosin, [982.

2. José Luis Cohellas. El Universo. Colección Salvat. Temas clave. Salvat Editores, S.A. N॰ 5, Barcelona, 1980.

3. Eli de Gortari. En tomo a la astronomía. Ed. Grijalbo, S.A., México, Barcelona, Buenos Aires, 1982.

4. D. Víctor Gebhardt. Los dioses de Grecia y Roma. I y II. Editora Nacional, S.A., México, 1951.

5. Robert Gaves. Los mitos griegos. I y II. Traducción de Luis Echávarri. \#" reimpresión en "El Libro de Bolsillo". Alianza Editorial, S.A., Madrid, 1987.

6. Antonio Ruiz de Elvira. Mitologi ClÁsica. Editorial Gredos, $2^{\mathrm{a}}$ Edición, Madrid, 1982.

7. Historia Universal Mlstrada europea americana. XII. Editorial Espasa Calpe, Madrid, 1911.

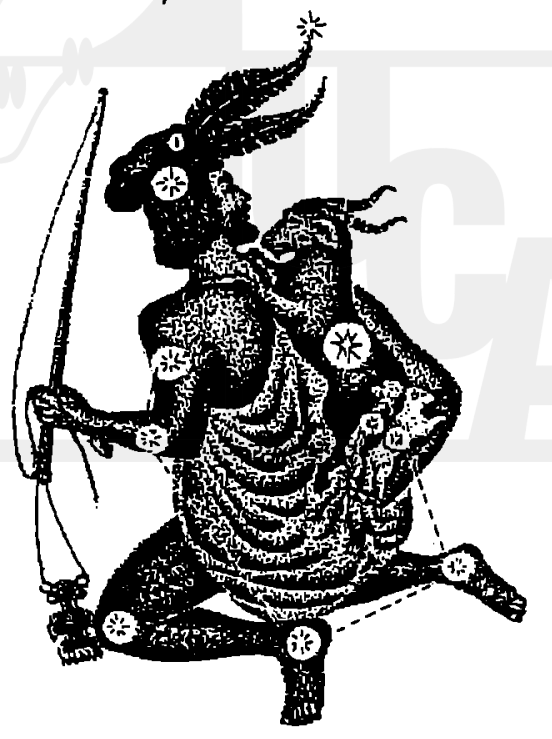

